\title{
STRATEGI PEMBERIAN REWARD UNTUK MENINGKATKAN MINAT \\ KUNJUNG MAHASISWA DI PERPUSTAKAAN POLITEKNIK NEGERI \\ SEMARANG
}

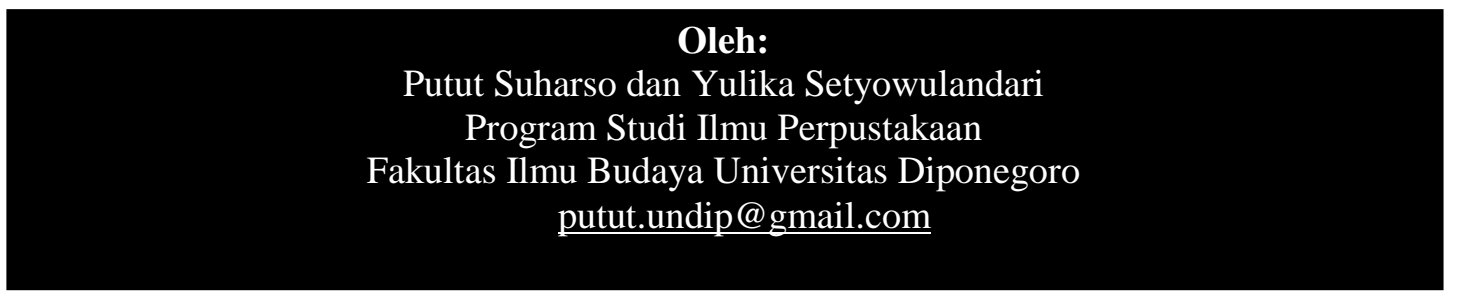

\begin{abstract}
In the freedom of information age, the openness and easiness of information access is important. The provision of data and information has become crucial for many people. The diversity of the information needs drive many information provider institutions work hard to fulfill those needs. However, neither institution can provide complex information needs or information sources perfectly. Thus, those information institutions should have a good solution in order to provide information for all users with different requirement. One of the actions is by building network or cooperation between information provider institutions. The research objective are, first to investigate the Indonesia - Malaysia digital library networks; secondly, to find out the drivers and obstacles of the networks. The research method is by web observation and literature study. The research output is a recommendation for the improvement of the Indonesia - Malaysia digital library networks and cooperation.

Keywords: library cooperation, library networking, IndonesiaMalaysia library
\end{abstract}

\begin{abstract}
ABSTRAK
Dalam era keterbukaan saat ini, penyajian data dan informasi sangat diperlukan untuk memberikan akses informasi seluas-luasnya kepada masyarakat. Keberagaman kebutuhan informasi, keterbatasan sumber daya informasi dan perubahan prilaku pengguna informasi menjadikan tidak satupun lembaga informasi yang dapat memenuhi semua kebutuhan penggunanya tersebut. Sehingga untuk memenuhi kebutuhan dan memberikan layanan yang optimal kepada pengguna maka diperlukan adanya kerjasama dan jaringan antar lembaga informasi. Salah satu lembaga informasi adalah perpustakaan yang akan di jadikan objek
\end{abstract}


dalam makalah ini. Sosialisasi dan pertukaran informasi dilakukan berbagai lembaga baik di dalam maupun di luar negeri. Seperti yang telah dilakukan oleh Kementrian Ristek Republik Indonesia dengan Ministry of Science, Technology and Innovation (MOSTI) Malaysia. Makalah ini akan membahas tentang jaringan informasi dan kerjasama perpustakaan digital antara Indonesia dan Malaysia, bentuk bentuk kerjasama yang ada dan faktor penunjang serta penghambat kerjasama tersebut. Metode pengumpulan data yang digunakan adalah dengan studi pustaka baik tercetak maupun online. Hasil dari makalah ini adalah meyediakan data dan informasi tentang jaringan informasi dan kerjasama perpustakaan antara Indonesia dan Malaysia yang dapat digunakan untuk memberikan rekomendasi baik untuk perpustakaan di Indonesia maupun di Malaysia dalam hal kerjasama.

Kata kunci: kerjasama perpustakaan, jaringan perpustakaan, Perpustakaan Indonesia-Malaysia 


\section{A. Pendahuluan}

erpustakaan saat ini
menjadi lembaga penyedia
sumber informasi bagi pengguna. Perpustakaan memiliki berbagai jenis koleksi yang dapat dimanfaatkan oleh semua pengguna secara gratis. Tuntutan pengelolaan perpustakaan secara baik, dari pemerintah maupun dari swasta adalah memperbaiki sistem kerja dan kinerjanya. Hal ini dilakukan sebagai upaya untuk mempertanggungjawabkan pengelolaan kepada lembaga penaung dan memberikan kemudahan pemustaka. Kemudahan pelayanan dan sikap profesional dalam melayani, menjadikan pengguna jasa merasa dihormati, tersanjung, dan merasakan kepuasan dalam mendapatkan pelayanan (Murniaty, 2006:1).

Kegiatan untuk mengenalkan layanan yang dimiliki kepada pemustaka tentu memerlukan strategi. Menentukan strategi layanan yang tepat di sebuah perpustakaan perguruan tinggi tentu memerlukan kreativitas dan inovasi oleh pengelola perpustakaan. Sebagai bentuk apresiasi kepada pemustaka di lingkungan sivitas akademika Politeknik Negeri Semarang, Perpustakaan memberikan reward atau Hadiah kepada dua kategori yaitu peminjam terbanyak dan pengunjung tersering. Tahun 2014 reward diserahkan langsung oleh Wakil Direktur I Ir. Achmad Jamaah M.T yang sangat mengapresiasi kegiatan yang diadakan secara rutin setiap tahun. Hal ini untuk mendorong meningkatnya minat pinjam dan kunjung perpustakaan. (http://lib.polines.ac.id/lib). Beliau akan menghimbau para Ketua Jurusan untuk membuat aturan syarat pengambilan KHS harus disertai dengan Surat Minimal Peminjaman Bahan Pustaka yang di keluarkan Perpustakaan, hal ini didasarkan pada pengalaman beliau pada waktu menjadi Dosen Wali. Beliau membuat aturan mahasiswa harus mempunyai pinjaman minimal 10 buku di perpustakaan. Hal tersebut ternyata menimbulkan dampak yang signifikan pada meningkatnya Indeks Prestasi pada mahasiswa yang diampunya.

Sebelum mempertahankan pemustaka tentu lembaga atau institusi tersebut harus diketahui atau dikenal oleh masyarakat terlebih dahulu. Untuk itu diperlukan promosi untuk mengenalkan "luaran dan isi" dari lembaga atau institusi tersebut. Promosi adalah forum pertukaran informasi antara organisasi dengan konsumen dan memiliki tujuan utama memberi informasi tentang produk atau jasa yang disediakan oleh organisasi, sekaligus 
membujuk konsumen untuk beraksi terhadap produk atau jasa itu. Sedangkan didalam dunia perdagangan promosi adalah usaha untuk memajukan dan meningkatkan popularitas barang yang dijual (Mustafa, 1996:20).

Salah satu lembaga yang memerlukan promosi adalah perpustakaan. Masih banyak orang yang beranggapan bahwa perpustakaan hanyalah sebuah ruangan sempit diujung koridor yang penuh debu, sepi dan tidak menarik sama sekali, ditambah dengan petugasnya yang galak dan koleksi bukunya yang sangat minim karena kebanyakan berisi buku-buku yang sudah dimiliki sehingga mereka enggan untuk berkunjung ke perpustakaan. Dari penilaian tersebut, maka sangat diperlukan promosi perpustakaan kepada para pemustaka.

Ada bermacam-macam kegiatan yang dapat dilakukan dalam promosi perpustakaan. Salah satunya adalah melalui pemberian reward (hadiah) kepada pengguna perpustakaan. Salah satu perpustakaan yang mengadakan kegiatan promosi perpustakaan tersebut adalah Perpustakaan Politeknik Negeri Semarang.

Biasanya, perpustakaan yang mengadakan kegiatan promosi dengan pemberian reward adalah perpustakaan sekolah yang pemustaka adalah siswa- siswi sekolah yang masih harus didorong untuk mau mengunjungi dan memanfaatkan koleksi yang ada di perpustakaan tersebut. Oleh karena itu dibutuhkan sesuatu untuk membuat siswa-siswi tersebut tertarik untuk mengunjungi dan memanfaatkan perpustakaan. Namun, di Perpustakaan Politeknik Negeri Semarang juga menggunakan cara ini untuk menarik pemustaka agar memanfaatkan koleksi. Hal ini tentu berbeda dengan perpustakaan perguruan tinggi lainnya.

Berdasarkan uraian di atas, penulis melakukan penelitian untuk mengetahui apakah mahasiswa Politeknik Negeri Semarang mengetahui adanya pemberian reward dan apakah reward itu berpengaruh terhadap mahasiswa untuk mengunjungi atau memanfaatkan koleksi yang ada di Perpustakaan Politeknik Semarang. Sesuai uraian di atas maka penulis berkeinginan melakukan kajian yang lebih mendalam, tentang "Pengaruh Promosi Perpustakaan Melalui Pemberian Reward terhadap Minat Kunjung Mahasiswa di Perpustakaan Politeknik Negeri Semarang”.

\section{B. Tinjauan Literatur}

\section{Promosi}

Menurut Halim dan Kennet G Mangun dalam Rangkuti (2009:49) 
promosi adalah kegiatan mengkomunikasikan informasi dari penjual kepada pembeli atau pihak lain dalam saluran untuk mempengaruhi sikap dan perilaku. Qalyubi dkk (2003:260) menjelaskan bahwa promosi perpustakaan merupakan aktivitas memperkenalkan perpustakaan dari segi fasilitas, koleksi, jenis layanan dan manfaat yang dapat diperoleh oleh setiap pemustaka.

\section{Konsep AIDA}

Untuk melakukan promosi, perusahaan harus merancang atau mendesain pesan-pesan menjadi efektif. Menurut Kotler dan Keller (2009:179) teori AIDA (Attention, Interest, Desire, and Action) merupakan suatu pesan yang harus mendapatkan perhatian, menjadi ketertarikan, menjadi minat, dan mengambil tindakan. Seorang pemasar harus menyadari bahwa pesan yang disajikan tentang AIDA mencakup:

a. Perhatian (Attention)

Menimbulkan perhatian pelanggan berarti sebuah pesan harus dapat menimbulkan perhatian baik dalam bentuk dan media yang disampaikan. Hal tersebut dapat dikemukan lewat tulisan dan gambar yang menonjol dan jelas, perkataan yang menarik atau mudah diingat, dan mempunyai karakteristik tersendiri.

b. Ketertarikan (Interest)
Tertarik berarti pesan yang disampaikan menimbulkan perasaan ingin tahu, ingin mengamati, dan ingin mendengar serta melihat lebih seksama. Hal tersebut terjadi karena adanya minat yang menarik perhatian konsumen akan pesan yang ditunjukkan.

c. Keinginan (Desire)

Pemikiran terjadi dari adanya keinginan ini, berkaitan dengan motif dan motivasi konsumen dalam membeli suatu produk. Motif pembelian dibedakan menjadi dua, yaitu motif rasional dan motif emosional. Motif rasional mempertimbangkan konsumen akan keuntungan dan kerugian yang didapatkan, sedangkan motif emosional terjadi akibat emosi akan pembelian produk.

d. Tindakan (Action)

Tindakan terjadi karena adanya keinginan kuat konsumen sehingga terjadi pengambilan keputusan dalam melakukan pembeli produk yang ditawarkan.

\section{Reward}

Secara etimologi reward berasal dari bahasa Inggris. Reward merupakan noun (kata benda) yang berarti ganjaran, hadiah, upah, pahala (Echols, 2008:485). Dalam kamus besar bahasa Indonesia padanan kata reward semakna dengan hadiah, yang berarti pemberian (kenangkenangan, penghargaan, penghormatan) (Depdiknas, 2012:472).

\section{Minat Kunjung}

Minat adalah suatu keinginan atau kecenderungan hati yang tinggi terhadap 
sesuatu (Sutarno, 2006:107). Sedangkan berkunjung berdasarkan Kamus Besar Bahasa Indonesia (Depdiknas, 2012:19) adalah pergi (datang) untuk menengok (menjumpai). Jadi dapat disimpulkan bahwa minat berkunjung adalah suatu keinginan seseorang untuk mendatangi suatu tempat atau event tertentu.

\section{Perpustakaan Perguruan Tinggi}

Perpustakaan perguruan tinggi ialah perpustakaan yang terdapat pada perguruan tinggi, badan bawahannya, maupun lembaga yang berafiliasi dengan perguruan tinggi dengan tujuan utama membantu perguruan tinggi mencapai tujuan utamnya (Tri Dharma perguruan tinggi) (Sulistyo-Basuki, 1993:51).

\section{Metode Penelitian}

\section{Desain dan Jenis Penelitian}

Jenis penelitian yang digunakan adalah penelitian korelasi, yaitu hubungan statistik berdasarkan ukuran kuantitatif menyangkut dua parameter atau lebih (Sulistyo-Basuki, 2006:114). Dalam metode ini dua variabel diteliti untuk melihat hubungan yang terjadi diantara keduanya tanpa mencoba untuk mengubah atau mengadakan perlakuan terhadap variabel tersebut.

\section{Populasi dan Sampel}

Populasi dalam penelitian ini adalah semua mahasiswa angkatan tahun 2011 Politeknik Negeri Semarang yang berjumlah 1.268 orang. Jumlah sampel dalam penelitian ini dihitung dengan menggunakan rumus Slovin dengan jumlah sampel 93 responden. Pemustaka yang dijadikan sampel dalam penelitian ini dipilih dengan menggunakan teknik disproportionate stratified random sampling.

\section{Variabel dan Indikator}

Variabel dalam penelitian ini ada 2 jenis, yaitu variabel bebas (independent variable) dan variabel terikat (dependent variable). Variabel bebas dalam penelitian ini adalah metode promosi dengan menggunakan reward. Indikatornya adalah:

1. Perhatian (Attention)

2. Ketertarikan (Interest)

3. Minat (Desire)

4. Tindakan (Action)

Variabel terikat dalam penelitian ini adalah minat kunjung mahasiswa ke Perpustakaan Politeknik Semarang. Indikatornya adalah:

1. Frekuensi kunjungan

2. Tujuan kunjungan 


\section{Jenis dan Sumber Data}

Dalam penelitian ini penulis menggunakan jenis data kuantitatif. Kemudian sumber data dari penelitian ini adalah data primer. Data primer dalam penelitian dikumpulkan dari kuesioner.

\section{Hipotesis}

Hipotesis dalam penelitian ini adalah diduga ada pengaruh positif promosi perpustakaan melalui pemberian reward terhadap minat kunjung kePerpustakaan Politeknik Negeri Semarang. Apabila dirumuskan melalui $\mathrm{H}_{0}$ dan $\mathrm{H}_{1}$ akan diperoleh sebagai berikut:

$\mathrm{H}_{0}$ : Tidak ada pengaruh signifikan antara variabel $\mathrm{X}$ (pemberian reward) dengan variabel $\mathrm{Y}$ (minat kunjung mahasiswa).

$\mathrm{H}_{1}$ : Ada pengaruh signifikan antara variabel $\mathrm{X}$ (pemberian reward) atas variabel Y (minat kunjung mahasiswa).

\section{Metode Pengumpulan Data}

Dalam penelitian ini, peneliti melakukan pengumpulan data dengan menggunakan teknik:

a. Kuesioner Dalam penelitian ini, kuesioner diberikan secara langsung kepada responden yaitu mahasiswa yang berkunjung ke Perpustakaan Politeknik Negeri Semarang. Kuesioner yang digunakan adalah pertanyaan bersifat tertutup dengan tujuan untuk memudahkan responden dalam menjawab serta mudah untuk dianalisis.

b. Wawancara dan hasilnya

Jenis wawancara yang digunakan dalam penelitian ini adalah wawancara terstruktur, yaitu wawancara dengan menggunakan daftar pertanyaan yang telah disiapkan sebelumnya. Wawancara dilakukan kepada 9 mahasiswa dengan jurusan yang berbeda mengenai tingkat pengetahuan mahasiswa terhadap promosi yang dilakukan oleh Perpustakaan Politeknik Negeri Semarang serta faktor-faktor apa saja yang mempengaruhi minat kunjung mahasiswa ke Perpustakaan Politeknik Negeri Semarang. Wawancara ini bertujuan untuk memperkuat hasil penelitian yang diperoleh dari data hasil pengolahan kuesioner.

c. Studi Dokumentasi

Pada penelitian ini metode dokumentasi dipergunakan untuk mengetahui data seperti nama responden, dan program studi responden tersebut.

\section{Teknik Pengolahan Data}

Tahap-tahap pengolahan data meliputi kegiatan:

\section{a. Editing}

Pada tahap ini penulis melakukan pengecekan terhadap kuesioner yang 
telah diisi oleh responden, meliputi pemeriksaan kelengkapan jawaban, keterbacaan tulisan, dan kejelasan makna jawaban.

b. Coding

Pada tahap ini akan diolah kuesioner tersebut dengan cara memberikan kode-kode tertentu pada jawaban dari kuesioner lalu akan dikelompokkan dalam kategori yang sama. Dalam penelitian ini pengkodean yang dimaksud adalah dengan cara memberi skor pada setiap jawaban dengan pengukuran sebagai berikut:
a. Sangat setuju
diberi skor 4
b. Setuju diberi skor 3
c. Tidak setuju diberi skor 2
d. Sangat tidak setuju diberi skor 1

c. Tabulasi

Data yang telah diperoleh sebelumnya disusun dalam bentuk tabel agar memudahkan dalam proses analisis data.

\section{Hasil dan Pembahasan}

\section{Analisis Data}

Analisis data merupakan kegiatan yang dilakukan setelah data dari seluruh responden atau sumber data lain terkumpul (Sugiyono, 2009:147). Dalam proses ini penulis menggunakan analisis deskriptif dan statistik.

\section{a. Tabel Distribusi Frekuensi}

Tabel distribusi frekuensi digunakan untuk menyajikan data dalam bentuk tabel yang masing-masing data dihitung presentasenya dan diuraikan.

b. Uji Validitas dan Reliabilitas

Sebelum instrumen penelitian digunakan untuk mengumpulkan data perlu dilakukan pengujian validitas. Hal ini digunakan untuk mendapatkan data yang valid dari instrumen yang valid. Menurut Sugiyono (2009:121) hasil penelitian yang valid adalah bila terdapat kesamaan anatara data yang terkumpul dengan data yang sesungguhnya terjadi pada objek yang diteliti. Pengujian instrumen dalam penelitian ini dilakukan dengan melihat masing-masing skor instrumen penelitian. Apabila koefisien validitas lebih kecil dari $\alpha$ $(5 \%=0,05)$ maka $\mathrm{H}_{0}$ ditolak atau dengan kata lain $\mathrm{H}_{1}$ diterima, artinya instrumen penelitian adalah valid.

Menurut Sugiyono (2009:121) instrumen yang reliabel adalah instrumen yang bila digunakan beberapa kali untuk mengukur obyek yang sama, akan menghasilkan data yang sama. Pengujian reliabilitas kuesioner penelitian menggunakan 
Alpha-Cronbach, yaitu melalui variasi skor butir pernyataan dengan variasi total skor keseluruhan butir pernyataan. Apabila koefisien reliabilitas lebih besar dari 0.6 maka secara keseluruhan pernyataan dinyatakan reliabel.

c. Uji Koefisien Korelasi

Model korelasi digunakan untuk mengetahui adanya hubungan peningkatan minat kunjungan mahasiswa ke Perpustakaan Politeknik Negeri Semarang yang disebabkan pemberian reward melalui kuesioner. Korelasi (r) merupakan istilah yang digunakan untuk mengukur kekuatan hubungan antar variabel. Korelasi yang terjadi antara dua variabel:

1. Korelasi positif $(r>0)$

2. Korelasi negatif $(\mathrm{r}<0)$

3. Tidak ada korelasi $(\mathrm{r}=0)$

4. Korelasi sempurna $(r=1)$

Analisis ini digunakan untuk menguji hipotesis apakah hipotesis diterima atau ditolak. Peneliti menggunakan kajian korelasi yang menggunakan uji hipotesis dengan rumus Koefisien Korelasi Product Moment, yaitu suatu alat statistik yang dapat digunakan untuk membandingkan hasil pengukuran dua variabel yang berbeda agar dapat menentukan tingkat hubungan antara variabel-variabel ini (Arikunto, 2010:314).

\section{Hasil Penelitian}

Berdasarkan perhitungan skor pemberian reward dapat diketahui bahwa sebanyak 11 responden atau sebanyak $12 \%$ menyatakan sangat setuju, sebanyak 43 responden atau sebesar $46 \%$ menyatakan setuju, sebanyak 35 responden atau sebesar 38\% menyatakan tidak setuju, dan sebanyak 4 responden atau sebesar 4\% menyatakan sangat tidak setuju. Hasil penelitian menunjukkan pemberian reward yang dilakukan oleh Politeknik Negeri Semarang menarik minat kunjung ke perpustakaan.

Berdasarkan hasil penggalian informasi lebih lanjut melalui wawancara dengan responden, mereka yang menjawab setuju karena reward ini dapat membuat mahasiswa yang awalnya jarang ke perpustakaan menjadi rutin berkunjung dan yang sudah sering berkunjung menjadi lebih bersemangat untuk datang ke perpustakaan.

Sedangkan untuk uji valid dinyatakan bahwa dari 22 pertanyaan yang terdapat dalam instrumen penelitian semua Dari hasil data semua 
instrumen pertanyaan nilai sig. $<\alpha$. Jadi dapat disimpulkan instrumen penelitian adalah valid.

Kemudian untuk nilai Cronbach’s dalam uji reliabilitas, nilai Alpha 0,622 (X) dan 0,602 (Y) lebih besar dari nilai 0,6 yang berarti semua pertanyaan yang ada dinyatakan reliabel.

Hasil Sig hitung dari output uji koefisiensi korelasi terlihat bahwa $\mathrm{H}_{0}$ ditolak. Jadi dapat disimpulkan bahwa $\mathrm{H}_{1}$ diterima yang artinya ada hubungan antara variabel pemberian reward dengan variabel minat kunjung mahasiswa dengan tingkat keeratan hubungan antara pemberian reward terhadap minat kunjung mahasiswa ke Perpustakaan Politeknik Negeri Semarang sebesar 0,836 atau $83,6 \%$ yang artinya sangat kuat hubungan antara kedua variabel tersebut. Hubungannya adalah positif artinya jika pemberian reward semakin tinggi maka minat kunjung mahasiswa ke Perpustakaan Politeknik Negeri Semarang semakin tinggi pula.

\section{Penutup}

\section{Simpulan}

Berdasarkan hasil analisis data dan pengolahan data dapat diambil simpulan sebagai berikut:

Kegiatan pemberian reward untuk meningkatkan minat kunjung mahasiswa ke Perpustakaan

Politeknik Negeri Semarang tergolong dalam kategori baik. Hal ini dibuktikan dengan hasil kuesioner yang telah dibagikan oleh peneliti dengan perolehan nilai 11\% menyatakan sangat setuju, sebanyak 46\% menyatakan setuju, $38 \%$ menyatakan tidak setuju, dan sebesar 4\% menyatakan sangat tidak setuju.

Terdapat hubungan yang positif antara pemberian reward dengan peningkatan minat kunjung mahasiswa ke Perpustakaan Politeknik Semarang. Hal ini terbukti dari hasil analisis statistik dengan rumus korelasi product moment diperoleh $r_{\text {hitung }}=0,836$ dan $\mathrm{r}_{\text {tabel }}=0,202$. Dari hasil tersebut nilai hitung $\left(\mathrm{r}_{\text {hitung }}\right)$ melampaui nilai tabel $\left(\mathrm{r}_{\text {tabel }}\right)$ karena nilai $\mathrm{r}_{\text {hitung }}$ lebih besar dari nilai $r_{\text {tabel}}$. Selain itu Sig hitungnya 0,000 maka lebih kecil dari 0,05 sehingga $\mathrm{H}_{0}$ ditolak. Jadi dapat disimpulkan bahwa $\mathrm{H}_{1}$ diterima yang artinya ada pengaruh antara variabel pemberian reward dengan variabel minat kunjung mahasiswa yaitu sebesar 83,6\%. Dari penelitian ini dapat dikatakan bahwa semakin tinggi kualitas kegiatan promosi melalui pemberian 
reward maka semakin tinggi pula minat kunjung mahasiswa ke Perpustakaan Politeknik Negeri Semarang. Strategi yang dirancang perlu mencakup aspek-aspek kekerapan pelaksanaan pemberian reward, pelibatan aktif pustakawan, keresmian penyelenggaraan dan kegiatan.

\section{Saran}

Berdasarkan pembahasan tersebut, ditemukan beberapa kekurangan yang membutuhkan saran-saran untuk dijadikan bahan pertimbangan dalam rangka meningkatkan minat kunjung mahasiswa Perpustakaan Politeknik Negeri Semarang, yaitu:

a. Agar minat kunjung masyarakat ke perpustakaan dapat meningkat, maka perlu diadakan kegiatan pemberian reward lebih sering dari yang sudah diadakan oleh perpustakaan yaitu 1 kali dalam setahun.

b. Pustakawan atau pegawai di Perpustakaan Politeknik Negeri Semarang diharapkan lebih gencar lagi dalam mempromosikan kegiatan ini karena masih banyak mahasiswa yang masih belum mengetahui bahwa Perpustakaan Politeknik
Negeri Semarang mengadakan kegiatan pemberian reward.

c. Untuk pengumuman kepada pemenang perlu ditambah dengan memberikan surat resmi yang ditandatangani kepala perpustakaan atau direktur Politeknik Negeri Semarang agar lebih terlihat resmi karena selama ini pemenang hanya diberi tahu melalui Short Message Service (SMS) dan diberitahu secara lisan di kelas.

\section{DAFTAR PUSTAKA}

Arikunto, Suharsimi. 2010. Prosedur Penelitian: Suatu Pendekatan Praktik. Jakarta: Rineka Cipta.

Departemen Pendidikan Nasional. 2012. Kamus Besar Bahasa Indonesia. Jakarta: Gramedia Pustaka Utama.

Echols, John M dan Hassan Shadily. 2008. Kamus Inggris-Indonesia. Jakarta: Gramedia Pustaka Utama.

Kotler, Philip dan Kevin Lane Keller. 2009. Manajemen pemasaran edisi 13 Jilid 1. Jakarta: Erlangga

Murniaty. 2006. "Promosi Jasa Pelayanan Referensi di Perpustakaan.” http://repository.usu.ac.id/bitstream /123456789/1817/3/06009263.pdf.t xt. Diunduh Minggu, 06 April 2014.

Mustafa, Badollahi. 1996. Promosi Jasa Perpustakaan. Jakarta: Universitas Terbuka.

Qalyubi, Syihabuddin, dkk. 2003. Dasar-dasar Ilmu Perpustakaan dan Informasi. Yogyakarta: Jurusan Ilmu Perpustakaan dan Informasi Fakultas Iadab IAIN Sunan Kalijaga. 
Rangkuti, F. 2009. Strategi Promosi yang Kreatif. Jakarta: Gramedia Pustaka Utama.

Sugiyono. 2009. Metode Penelitian Kuantitatif, Kualitatif dan $R \& D$. Bandung: Alfabeta.

Sulistyo-Basuki. 1993. Pengantar Ilmu Perpustakaan. Jakarta: Gramedia Pustaka Utama.

Syam. Penyerahan Reward Pemustaka. http://lib.polines.ac.id/lib/index.ph p/artikel/kegiatan-perpustakaan/92penyerahan-reward-pemustaka Akses Tanggal 12 Desember 2014 